\title{
Estudo Prospectivo e Tecnológico do Trigo Sarraceno (Fagopyrum esculentum) com Ênfase na Produção de Cerveja
}

\author{
Prospective Study on Buckwheat (Fagopyrum esculentum) With
} Emphasis on Breer Production

\author{
Viviane Cristina Buge Brasil ${ }^{1}$ \\ Rafael Benjamin Werneburg Evaristo ${ }^{1}$ \\ Bernardo Pontes Guimarães ${ }^{1}$ \\ Grace Ferreira Ghesti ${ }^{1}$ \\ ${ }^{1}$ Universidade de Brasília, Brasilia, DF, Brasil
}

\begin{abstract}
Resumo
O trigo sarraceno ou mourisco é um pseudocereal amplamente empregado na indústria alimentícia, tendo em vista características que lhe conferem especificidades interessantes: não possui glúten, é rico em polifenóis de interesse farmacológico e tem cultivo facilitado e eficiente. O cultivo do grão é explorado em diversas partes do mundo, tendo grande interesse para o mercado de exportação brasileira. Seu uso para produção de cerveja demonstra a versatilidade de aplicações desse insumo, podendo ainda agregar propriedades especiais ao produto final. Diante disso, o trabalho foi realizado em duas vertentes de investigação, a pesquisa por patentes e por artigos científicos, a fim de explorar a produção de tecnologias e trabalhos acadêmicos relacionados ao trigo sarraceno, em especial para produção de cerveja. Tal busca identificou o alto desenvolvimento tecnológico desse insumo associado às patentes das empresas depositantes, bem como a disparidade com relação à produção de artigos, ainda que ambos tenham crescido nos últimos 20 anos.
\end{abstract}

Palavras-chave: Trigo Sarraceno. Cerveja sem Glúten. Tecnologia de Fabricação de Cerveja.

\begin{abstract}
Buckwheat is a pseudocereal largely used in many culinary recipes due to its starch content comparable to other cereals commonly used; nevertheless, some of its characteristics make buckwheat very interesting, among them: gluten free, rich in pharmaceutically-interesting polyphenols, easy and efficient production. The crop culture is worldwide, what makes it an agricultural commodity for the Brazilian and international market. The usage of buckwheat in beer brewing shows one of its many uses, increasing special properties to the final product. In light of that, this work was divided into patent and scientific paper research in order to explore new technologies and scientific work related to buckwheat, especially towards beer. This research identified a high technological development of this pseudocereal related to companies' patents, as well as a discrepancy with the number of scientific papers published, even though both has grown for the last 20 years.
\end{abstract}

Keywords: Buckwheat. Gluten free Beer. Brewing Technology.

Área Tecnológica: Tecnologia de Alimentos. Tecnologia das Bebidas. Tecnologia Cervejeira. 


\section{Introdução}

O trigo sarraceno (Fagopyrum esculentum), também chamado de trigo mourisco, é uma espécie vegetal dicotiledônea de ciclo curto. Apresenta características muito semelhantes aos cereais, como o trigo, porém, por não ser uma gramínea, é chamada de pseudocereal (CHRISTA; SORAL-ŚMIETANA, 2008).

Seu ciclo de cultivo é de 30 dias e é muito utilizada para rotações de cultura. Seu desenvolvimento permite exterminar a maioria das ervas daninhas que competem por recursos do solo, sendo essa cultura extremamente econômica para produção, pois não requer pesticidas e necessita de baixo índice pluviométrico. Além disso, os gastos com fertilizantes são mínimos, já que a planta é capaz de se nutrir com os resquícios de culturas anteriores. Cresce em solos ácidos, como o do cerrado brasileiro, e ainda é utilizado para preparo de solo de cultivos orgânicos, pois além de eliminar as ervas daninhas, é capaz de adicionar até $3.000 \mathrm{~kg}$ de material orgânico por hectare de solo plantado (BOLAND, 2016).

O trigo sarraceno é comumente desenvolvido na indústria na forma de farinha para a fabricação de pães, panquecas e diversos tipos de alimentos sem glúten. Seu uso tem sido sumarizado pelo acréscimo de proteínas aos produtos para celíacos, já que esse grão tem alto valor proteico, mas não contém o glúten em sua composição. Os seus valores de aminoácidos superam os de proteínas isoladas da soja e caseína, por exemplo. Sua composição tem alto valor nutricional, sendo também fonte para produtos farmacêuticos, por conta de sua concentração de rutina, aproximadamente, $218 \mathrm{mg} / \mathrm{kg}$ de farinha. A disponibilidade de amido no grão também é alta, sendo que $33 \%$ desse amido se refere ao amido resistente, o qual pode melhorar o metabolismo de colesteróis e prevenir doenças associadas ao sistema gastrointestinal. Por isso, o consumo do grão é tido por muitos artigos e revistas como um alimento preventivo para diversas doenças (TOMOTAKE et al., 2002; KREFT; FABJAN; YASUMOTO, 2006).

A pesquisa acadêmica relacionada ao trigo sarraceno traz, em grande maioria, dados de composição e sua utilização em alimentos variados, sendo constantemente publicado em periódicos nas áreas de nutrição, medicina e tecnologia de alimentos. Em diversos artigos que comparam materiais, principalmente os pseudocereais, vê-se que as propriedades benéficas do grão são constantemente exaltadas frente aos demais, por isso, também, alguns artigos tendem a revisar a composição do grão tratando de maneira imparcial para que as beneficies e seus malefícios sejam entendidos pela comunidade científica. Alguns raros artigos e trabalhos científicos (cerca de $0,2 \%$ de toda produção bibliográfica no tema) relatam a utilização das cascas e palhas do trigo sarraceno como fonte lignocelulósica para processos termoquímicos (como pirólise e gaseificação), a fim de converter esses subprodutos do beneficiamento do grão como matéria-prima para produção de energia renovável via conversão térmica e novos materiais (biossensores) (ELSAYED et al., 2017; KNOX et al., 2018; LAZDOVICA et al., 2017).

Já as patentes sobre o tema demonstram um mercado criativo, no que diz respeito à produção de alimentos sem glúten, por isso, o desenvolvimento de máquinas para sua manufatura, crescimento e utilização em outros alimentos é recorrente. As pesquisas que se distanciam do 
tema principal, alimentação, dizem respeito à extração de compostos específicos do grão ou folha, como a rutina. Outras vertentes fazem indicação do uso do material para tratamentos na medicina chinesa. Entretanto, o mercado de cerveja produz mais patentes e artigos relacionados ao trigo sarraceno do que qualquer outro setor produtivo. As cervejas têm como insumo principal o malte de cevada que, por sua vez, possui glúten em sua composição. A utilização de outros cereais e grãos na cerveja, juntamente com o malte, é chamada de adjuntos (comercialmente empregados, o milho e o arroz). O trigo sarraceno, por sua vez, confere a bebida não só a carga de amido necessária para processo cervejeiro como também as propriedades inerentes a esse cereal já condicionadas a outros produtos alimentícios (RIBEIRO, 2016; BUIATTI; BERTOLI; PASSAGHE, 2018).

O mercado internacional do trigo sarraceno mobilizou em 2017 cerca de 835 milhões de toneladas divididas entre os países exportadores e importadores (mostrando-se produto com certa relevância no mercado de produtos agrícolas).

Segundo dados de Simoes (2019), referente ao ano de 2017, é possível observar na Figura 1 que os Estados Unidos (13\%) e a Alemanha (11\%) são os países que mais exportaram trigo sarraceno no mundo, ainda é possível observar que, na América do Sul, o Brasil se destaca como maior exportador do grão $(2,6 \%)$, comparado à quantidade comercializada pelo Reino Unido. Já no que diz respeito aos países importadores do grão, destaca-se a Polônia (7,5\%) no continente europeu, Peru (13\%) no continente sul-americano e Canadá (11\%) no continente norte-americano. Pela pouca expressividade em importação, o Brasil não é descrito nos dados da fonte pesquisada, uma análise mais profunda das exportações e das importações de trigo sarraceno é apresentada na Figura 2.

Figura 1 - Dados percentuais dos países exportadores de trigo sarraceno do ano de 2017

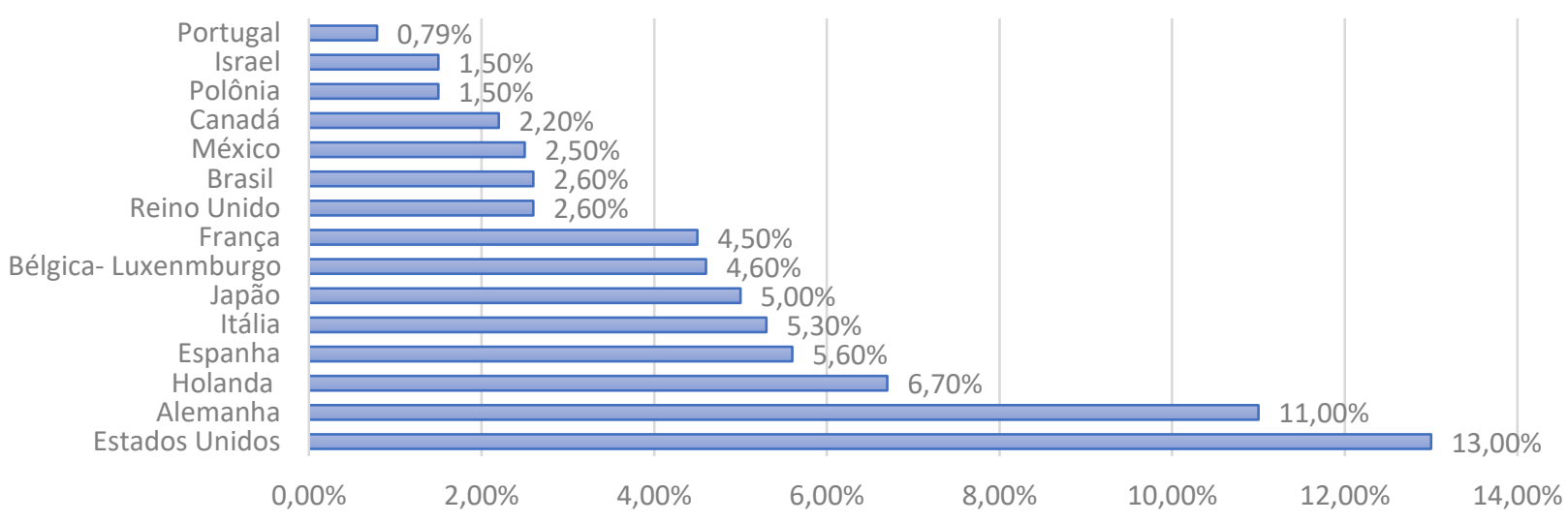

Fonte: Simoes (2019) 
Figura 2 - Dados de Importação e Exportação de Trigo Sarraceno no Brasil retirados da plataforma Comex Stat do Ministério da Economia

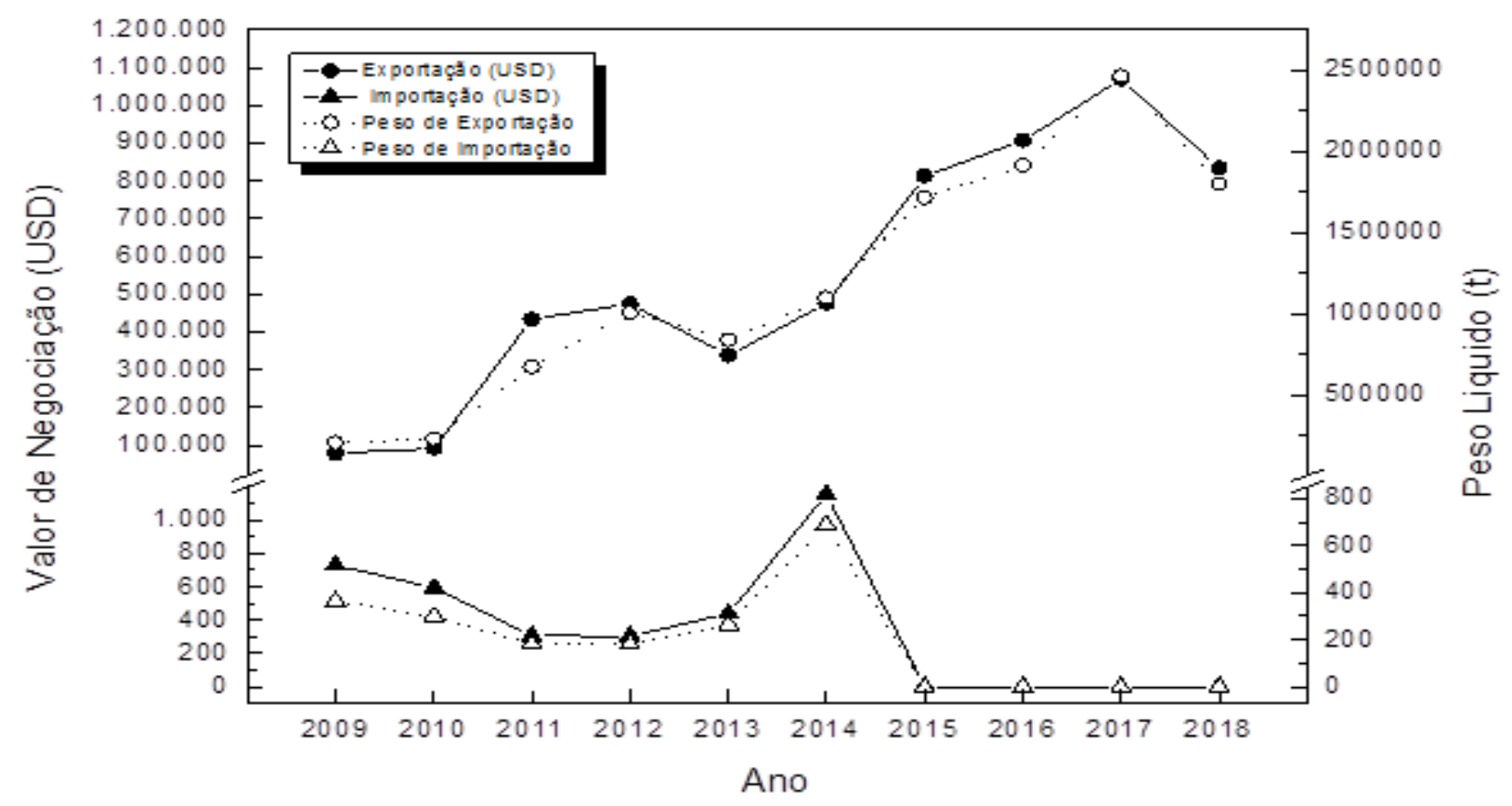

Fonte: Elaborada pelos autores deste artigo a partir dos dados da plataforma Comex Stat (2019)

Assim, a Figura 2 apresenta os dados de importação/exportação do trigo sarraceno no âmbito nacional. Os números de exportação seguem uma tendência crescente até o ano de 2017, com exceção de uma pequena queda no ano de 2013, mas que retoma a projeção destacada. O nível de exportação brasileira chegou ao patamar de 2,5 milhões de toneladas em 2017, enquanto o peso de importação se mantém em 0 (zero) toneladas desde 2015. Esses dados podem demonstrar que a produção brasileira conseguiu suprir a demanda nacional (COMEX STAT, 2019).

Ainda na Figura 3, os valores de negociação e o seu peso líquido para os casos de importação e exportação foram comparados e, apesar de um ponto em 2011 demonstrar uma pequena discrepância, nos demais anos, é possível notar que o valor acompanha a produção do grão. Esse aumento do preço na safra de 2011 pode ter sido ocasionado pela forte seca $e$ pelos consequentes incêndios na Rússia em 2010, o que levou à perda de um terço da safra do país nesse ano. Tendo a Rússia uma forte cultura de consumo e produção do grão, o país foi fechado para exportação na tentativa de preservar o mercado interno. Por isso, países asiáticos podem ter aumentado a demanda do produto brasileiro, dessa forma, a lei de oferta e procura se fez válida aos produtores brasileiros, aumentando seu valor de mercado. Esse tipo de ação demonstra que o fator determinante para a compra do produto brasileiro são sua produção $e$ demanda internacional (APK-INFORM INFORMATION AGENCY, 2011; KUZMICHEV, 2010).

Em 2018, deu-se início a uma queda da exportação, com número em torno de 750.000 toneladas de déficit em relação a 2017, ano que o comércio internacional desse produto alcançou seu maior patamar. Consequentemente, os produtores aumentaram a safra de 2019, considerando seu histórico de exportação. Projeções como essas somadas ao estudo que indica a queda da procura do mercado internacional frente à produção brasileira podem gerar um 
hiperabastecimento do trigo sarraceno nos estoques das empresas produtoras (MENAFN, 2018). Baseando-se na queda do comércio internacional desse pseudocereal, é importante solucionar o hiperabastecimento do produto no mercado interno brasileiro diversificando o uso desse insumo, que tem grande valia se considerados os seus parâmetros nutricionais e possível exploração de outras características no meio científico. Dessa forma, essa prospecção foi conduzida para indicar caminhos tecnológicos viáveis para sua utilização, tendo sido especificada a matéria deste estudo para utilização no incremento das funcionalidades das cervejas, em vista de estar próximo das características dos cereais adicionados às cervejas comumente comercializadas.

\section{Metodologia}

Em decorrência da importância comercial do trigo sarraceno, a prospecção baseou-se em duas perspectivas: tecnológica e científica, realizadas por meio de pesquisas de patente e artigos científicos, respectivamente. As buscas ocorreram no mês de abril de 2019, adotando-se duas bases de dados como fonte de pesquisa, sendo elas: a plataforma de busca de patentes Questel Orbit Intelligence (Orbit) e Web of Science para artigos científicos indexados, para o período de 1999 a 2018.

Foram selecionadas palavras-chave como "buckwheat" (trigo sarraceno, em inglês), "beer" (cerveja, em inglês), "gluten free" (livre de glúten ou sem glúten, em inglês), "brew" (bebida fermentada, em inglês) e "beverages" (bebidas, em inglês), relacionando trigo sarraceno com a produção de cerveja, utilizando para variação dos termos o caractere de truncamento "*" $e$ os operadores booleanos "AND" e "OR" para combinação dos termos. Os termos foram assim escolhidos para melhor representar o campo de pesquisa e a produção tecnológica relacionados ao trigo sarraceno, ou seja, sua aplicação em alimentos sem glúten, bem como restringindo a busca para o setor cervejeiro e de bebidas com os termos "beer" e "beverage".

A busca na base Orbit foi realizada por meio da inserção dos termos de busca em "search", "document search", "article title", "abstract", "language: English". Na plataforma de busca Web of Science, realizou-se as buscas selecionando-se a opção "busca avançada" e, na sequência, inserindo as palavras-chave no "título" e no "resumo". O qual foi utilizado para a reprodução das buscas realizadas e geração de figuras e gráficos específicos a partir dos resultados obtidos.

\section{Resultados e Discussão}

A Tabela 1 apresenta, respectivamente, um resumo geral dos resultados obtidos por meio dos bancos de patentes na plataforma de busca Orbit e Web of Science. Quando se busca nos bancos de dados a palavra "buckwheat", observa- se previamente que 80,5\% das comunicações foram pedidos de patente, enquanto $19,5 \%$ foram classificados como artigo. Portanto, o trigo sarraceno apresenta ampla aplicação industrial, o que justifica o número de patentes ser superior ao número de artigos. Logo, entende-se que por ser um pseudocereal cultivado em diversos países, sua aplicação industrial é mais rentável, não sendo objeto usual de pesquisas. 
Tabela 1 - Pesquisa por combinações de palavras-chave na plataforma de busca on-line Orbit e Web of Science com os termos destacados no período de 1999-2018

\begin{tabular}{cccccccc}
$\begin{array}{c}\text { Número } \\
\text { Da busca }\end{array}$ & Palavra & Operador & Palavra & OPerador & Palavra & Patentes & Artigos \\
$\mathbf{1}$ & Buckwheat & - & - & - & - & 12545 & 3330 \\
$\mathbf{2}$ & Buckwheat & AND & Food & - & - & 3070 & 810 \\
$\mathbf{3}$ & Buckwheat & AND & Brew* & - & - & 434 & 35 \\
$\mathbf{4}$ & Buckwheat & AND & Gluten Free & - & - & 41 & 252 \\
$\mathbf{5}$ & Buckwheat & AND & Gluten & - & - & 381 & 296 \\
$\mathbf{6}$ & Beer & AND & Gluten Free & - & - & 12 & 92 \\
$\mathbf{7}$ & Beer & AND & Gluten & - & - & 216 & 137 \\
$\mathbf{8}$ & Buckwheat & AND & Beer & - & - & 99 & 32 \\
$\mathbf{9}$ & Buckwheat & AND & Beverages & - & - & 515 & 34 \\
$\mathbf{1 0}$ & Buckwheat & AND & Beer & AND & Gluten Free & 2 & 20 \\
$\mathbf{1 1}$ & & \multicolumn{2}{c}{ 2 OR 3 OR 4 OR 6 OR 9 } & & 3817 & 1062 \\
\hline
\end{tabular}

Fonte: Elaborada pelos autores deste artigo (2019)

Conforme mostra a Figura 3, além dos números da Tabela 1, vê-se que houve concentração da produção de documentos patentários do ano de 2014 a 2018, quando o número de documentos superou $10 \%$ das produções de todos os anos. Os últimos quatro anos concentraram $60,2 \%$ da documentação de patentes por todo o mundo, enquanto o percentual para a produção científica foi de $45,9 \%$ para o mesmo período.

Figura 3 - Quantidade de depósito de patentes e artigos nos últimos 20 anos sobre trigo sarraceno, recuperados pela plataforma de busca por patentes Orbit e banco de dados Web of Science

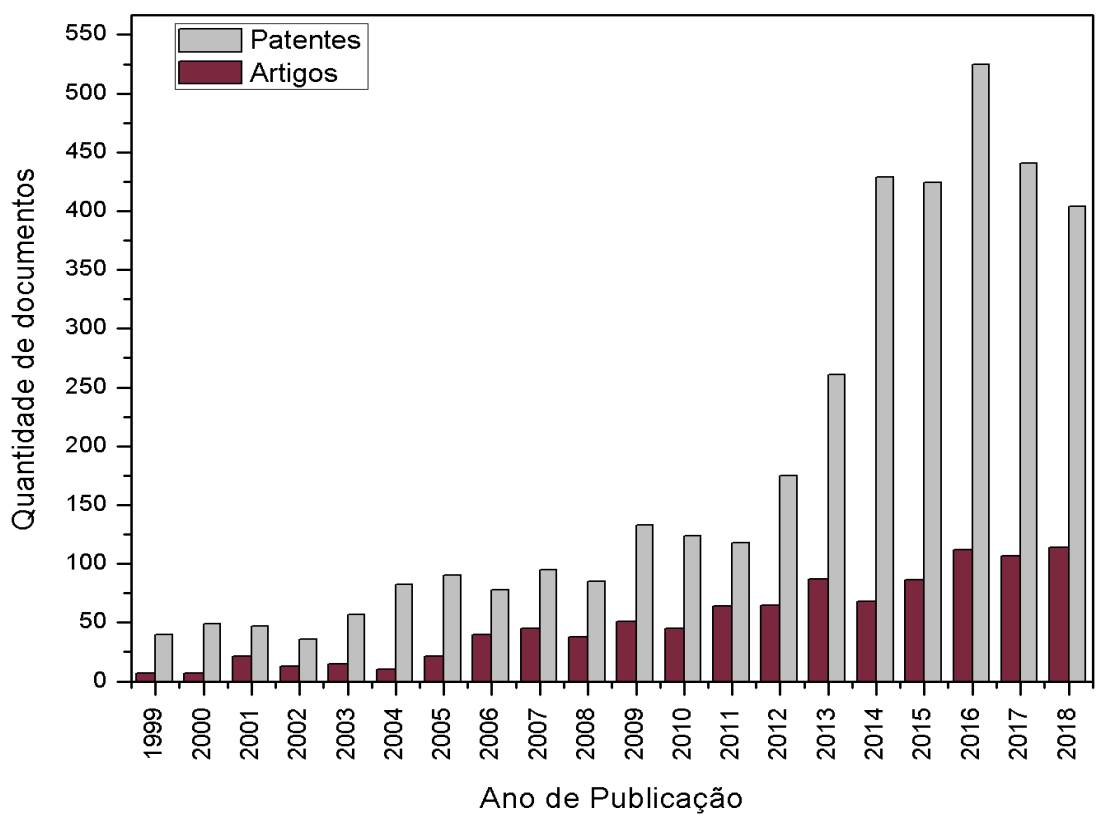

Fonte: Elaborada pelos autores deste artigo (2019) 
O número de patentes e de artigos quando combinados os termos "buckwheat", "beer" e "gluten free" diminui drasticamente (cerca de 1.000 vezes). Esse operador de restrições avaliou diretamente o emprego do pseudocereal na produção de cerveja sem glúten. Como no Brasil e em diversos países não é possível proteger por meio de patentes receitas alimentícias, em função da presença de anterioridade e insuficiência descritiva, os números decaem consideravelmente como destacado. Importante ressaltar que, analisando os últimos três anos, é possível observar uma constante no número de publicações de artigos, em paralelo com a produção de patentes, pode-se salientar uma tendência do mercado em proteger suas tecnologias, sendo seguida pela academia que pode dar preferência pela proteção no formato de patentes em detrimento da publicação de artigos científicos (análise do ponto de vista da maneira como as empresas do ramo alimentício se destacam no desenvolvimento de novas tecnologias).

A Figura 4 apresenta a distribuição dos países pela quantidade de patentes demonstrando, assim, de maneira assertiva, que o desenvolvimento tecnológico para uso e beneficiamento do grão se concentra nos países onde há uma cultura de consumo do grão em suas receitas diárias, como: China (CN), Japão (JP), Rússia (RU) e República da Coreia (KR). Em destaque, encontra-se a China, fator associado às políticas de proteção de tecnologias por patentes que é extensivamente difundida e bastante usada em função do forte ecossistema de inovação existente no país (OLIVEIRA et al., 2018).

Figura 4 - Países com maior número de depósitos de patentes

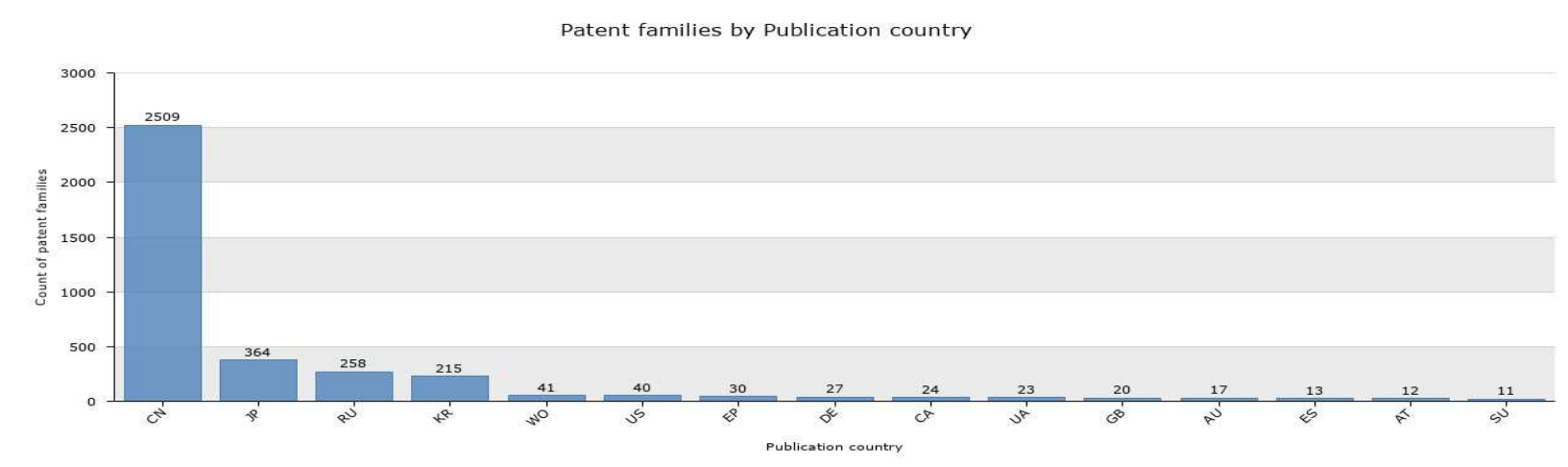

Fonte: Orbit (2019)

A China com destaque no número de depósitos de patentes (2.509) ultrapassa o segundo colocado em quantidade, Japão (364), em quase sete vezes, fruto tanto da ascensão global do país como superpotência comercial como também de empresas específicas no ramo de alimentos. Nesse caso específico (dentro dos termos pesquisados), uma empresa se destaca no ramo cujo alcance foi expandido a partir de 2001 com seu estabelecimento em diversas cidades. A empresa privada nominada Anhui Yanzhifang Food Ltd. (como apontado na Figura 5 como destaque no número de depósitos de patentes) foi modernizada e expandida em 2009. Dados resultantes de uma equipe própria de PD\&I que produz números expressivos de documentos patentários, sendo o trigo sarraceno uma de suas matérias-primas mais utilizadas e empregadas nos processos produtivos de produtos sem glúten. 
Tratando-se ainda das empresas e das instituições, a Figura 5 mostra o ranking de instituições que protegeram patentes sobre o pseudocereal. Essa figura reforça a tendência de empresas chinesas na utilização desse material e em sua produção tecnológica.

Figura 5 - Instituições com maior número de depósitos de patentes

Patent families by Assignees

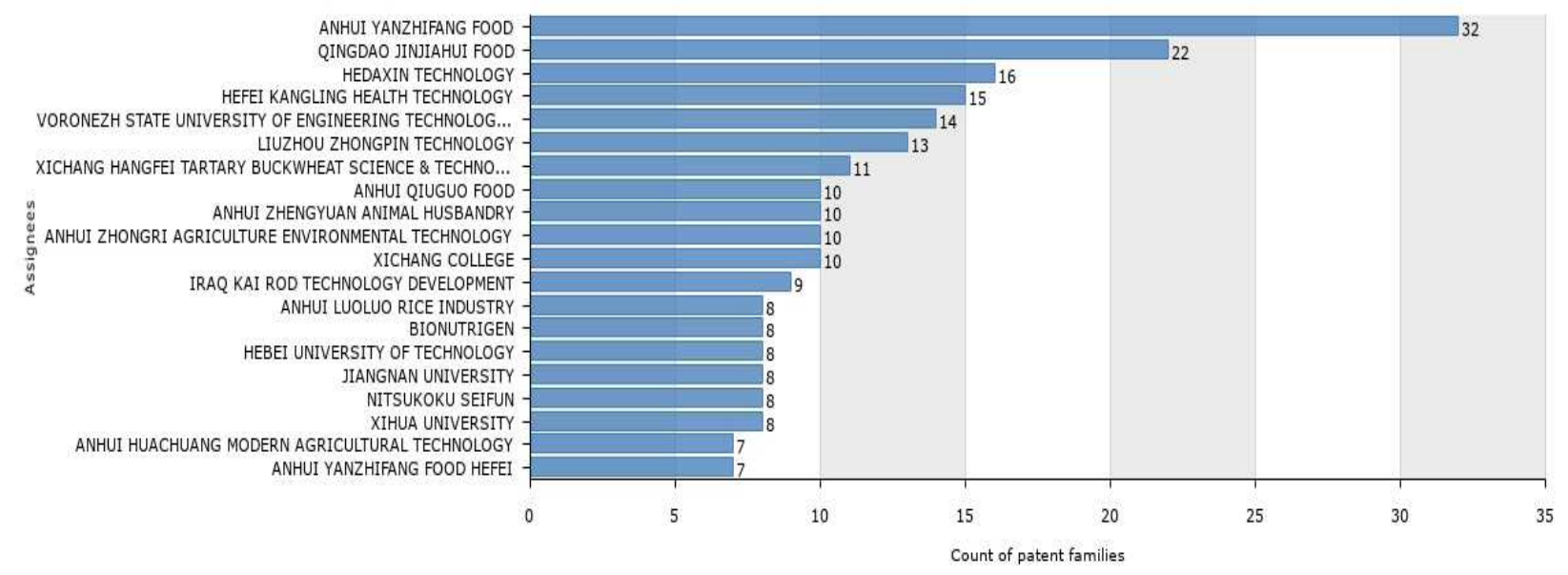

๑Questel 2019

Fonte: Orbit (2019)

No cenário mundial de proteções de patentes, o Brasil está em $16^{\circ}$ lugar. Foram nove patentes protegidas no país, discriminadas na Tabela 2. Pode-se observar que somente uma foi desenvolvida e protegida no Brasil (BR102013003182). As demais foram produzidas em outros países e aqui também foram protegidas por meio de escritórios internacionais. $\mathrm{O}$ exemplo de empresa mais conhecida no setor é a Heineken que apresentou dois documentos patentários para a produção de cervejas sem glúten, sendo uma delas por meio do uso do trigo sarraceno e arroz.

A fabricação de cerveja envolve essencialmente quatro elementos: água, malte, lúpulo e levedura (KUNZE, 2004). O malte em sua grande maioria é originado da cevada a partir do processo de malteação (germinação controlada e tratamento térmico), possibilitando ao grão a presença de enzimas capazes de digerir seu conteúdo amiláceo que virá a ser transformado nos açúcares fermentescíveis e proporcionará o conteúdo alcóolico da bebida. A possibilidade de incremento de outras variedades de matrizes amiláceas no processo (adjuntos) proporciona uma infinidade de receitas e diferentes tipos de cerveja. É nessa perspectiva que o incremento do trigo sarraceno para as cervejas se faz presente e vem sendo desenvolvido por empresas e pesquisadores, além disso, essa prática abre novos caminhos para produtos comerciais sem glúten com um nicho crescente de consumidores. 
Tabela 2 - Pedidos de proteção por meio de patentes no Brasil

\begin{tabular}{|c|c|c|}
\hline $\begin{array}{l}\text { NúMERO DA PUBLI- } \\
\text { CAÇÃO }\end{array}$ & Título & InSTITUIÇÃo/DEPOSITANTE \\
\hline ZA9902543 & Gluten-free beer & HEINEKEN ITÁLIA \\
\hline CA2268506 & Gluten-free beer containing rice malt and buckwheat & HEINEKEN ITÁLIA \\
\hline BR 102013003182 & Gluten-free beer production process & VITOR CARLOS VEIT* \\
\hline NO20001614 & $\begin{array}{l}\text { Puffed food starch products and } \\
\text { method for making the same }\end{array}$ & QUAKER, QUAKER OATS* \\
\hline US20080138485 & Snack chip containing buckwheat hulls & FRITO LAY* \\
\hline GB9826976 & Puffed cereal cakes & HIGH QUALITY FOOD S.A \\
\hline KR20070091391 & Fermented bubble drink with functionality & TAE GOOK KWON \\
\hline CN102987383 & $\begin{array}{l}\text { Composition for balancing gut microbiota } \\
\text { and preparation and the uses thereof }\end{array}$ & DAD JA SHANGHAI \\
\hline CA2923633 & Soft biscuit with slowly available glucose & GENERAL BISCUITS \\
\hline
\end{tabular}

Fonte: Elaborada pelos autores deste artigo (2019)

A patente brasileira citada não foi associada a qualquer instituição e se trata de uma invenção que abrange o processo de fabricação de uma cerveja sem glúten por meio da utilização de matérias-primas que têm essa proteína em sua composição, mas que é degradada pela adição de proteases das classes e subclasses da pepsina, tripsina, quimotripsina, papaína, bromelina, quimosina, ficina e das enzimas das subclasses da mucopepsina, da carvoxipeptidase A, da carboxipeptidase B ou a gly-xaa carboxipeptidase, conforme o tipo de grão e cervejas utilizadas (VEIT, 2014).

Existe uma diferença relevante nessa patente que se refere ao cultivo de leveduras em meios sem glúten, para evitar a potencial contaminação cruzada provinda do crescimento celular da Saccharomyces, já que não pode haver adição da proteína após a quebra enzimática na fase quente do processo. Para essa etapa, foi sugerida que o meio de cultivo também pudesse sofrer a quebra enzimática da produção do mosto ou serem cultivadas em meios já isentos dessa proteína (VEIT, 2014). Logo, pode-se sugerir que, para o uso do estado da arte da patente brasileira, utilize-se um meio de crescimento feito a partir de Trigo Sarraceno, que tem em sua composição amido e aminoácidos essenciais para a reprodução das leveduras.

A Figura 6 demonstra de maneira gráfica a predominância dos domínios tecnológicos utilizados para as patentes que envolvem o trigo sarraceno. Visto que a maioria delas está relacionada com a química dos alimentos, fato esperado pela quantidade de nutrientes, proteínas e aminoácidos em sua composição propositalmente integrados às receitas com a adição do trigo sarraceno. Além de seus benefícios na alimentação humana e na agricultura, outro fator de importância a ser considerado é a sua vasta utilização em culturas de grande população, como a asiática, fator que acresce em número as pesquisas e as demais produções tecnológicas derivadas desse alimento. 
Figura 6 - Relação de domínio tecnológico de patentes depositadas

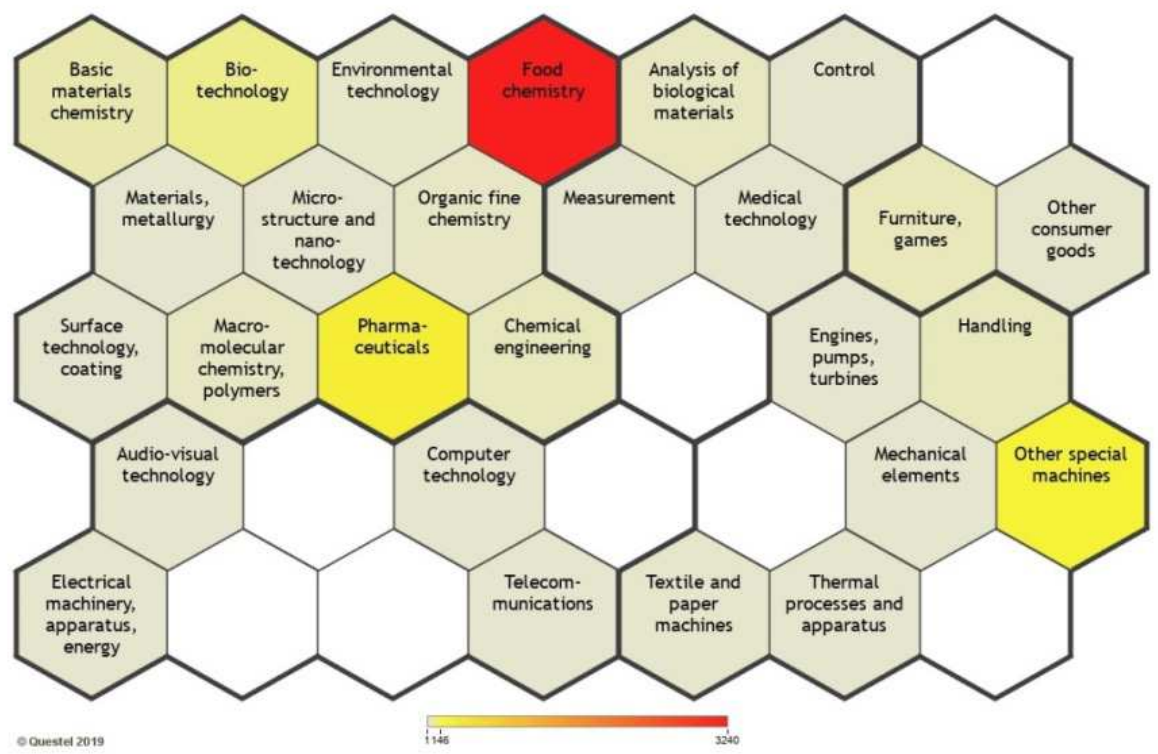

Fonte: Orbit (2019)

Destoante do tema que engloba a maioria das patentes, mas não menos importante, em segundo lugar no que diz respeito ao domínio tecnológico das patentes, encontra-se o potencial farmacêutico do trigo sarraceno. Tal relevância desse domínio entre a área de proteção das patentes era esperado devido a diversos estudos de concentração de rutina encontrada na planta, principalmente na flor do trigo sarraceno, bem como os estudos da medicina tradicional chinesa, que consideram o trigo sarraceno um medicamento. A concentração de rutina tem sido maior que a esperada em outras culturas (KREFT; FABJAN; YASUMOTO, 2006) e proporciona a vantagem de não gerar competição entre a produção alimentícia, pois se trata da exploração de todo o material, que até então é utilizado em sua maioria como palhagem.

Outra área destacada na Figura 6, quase no mesmo patamar que a área farmacêutica, corresponde às máquinas especiais. As patentes nessa área se referem ao tratamento do grão em sua manufatura relacionadas a novos tipos de maquinário para moer, descascar e tratar o trigo sarraceno conservando sua composição primitiva.

Com a análise da Figura 6, é possível ter um panorama geral de como as tecnologias relacionadas ao trigo sarraceno estão distribuídas, corroborando vários aspectos explicitados, esse panorama fica mais evidente quando se faz a análise das patentes e das famílias de patentes por meio da Classificação Internacional de Patentes (CIP) como apresentado na Figura 7. Através da CIP, é possível identificar a quais áreas e subáreas se dividem cada documento, entrando nos detalhes da tecnologia, podendo aprofundar o entendimento generalizado por domínios tecnológicos como apresentado na Figura 7. 
Figura 7 - Patentes localizadas com as CIPs retiradas do Orbit

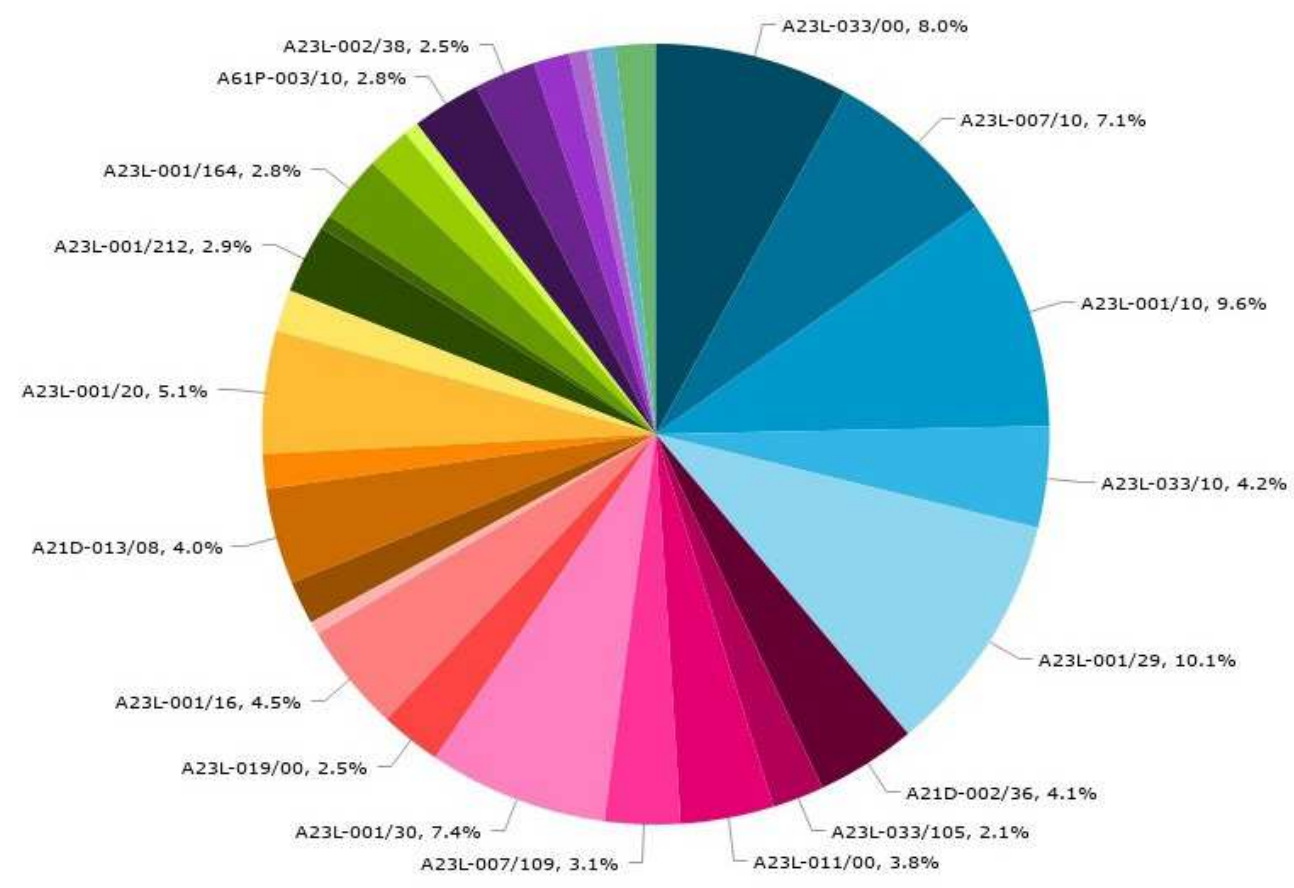

(c) Questel 2019

Fonte: Orbit (2019)

Por meio da Figura 7 foi construída a Tabela 3 para melhor entendimento das classes e subclasses das patentes dispostas neste estudo. Dessa maneira, pode-se ver que as categorias A23L são as mais citadas, equivalendo a 75,7\% do total de patentes da Figura 8 , as outras categorias foram de A21D com 8,1\% e A61P com apenas 2,8 \%.

Tabela 3 - Definição das categorias e subcategorias das CIP de acordo com o INPI das subseções encontradas na Figura 7

\begin{tabular}{|c|c|c|c|}
\hline Classe & DESCRIÇÃo & SubCLASSE & AtribuiçÃo \\
\hline A21 & $\begin{array}{l}\text { Cozedura ao forno; equipamento } \\
\text { para preparo ou processamento } \\
\text { de massas; massas para } \\
\text { cozedura ao forno }\end{array}$ & $\mathrm{D}$ & $\begin{array}{l}\text { Tratamento, p. ex. conservação, de } \\
\text { farinhas ou massas, por exemplo, pela } \\
\text { adição de matérias; cozimento; produtos } \\
\text { de panificação; conservação dos mesmos }\end{array}$ \\
\hline A23 & $\begin{array}{c}\text { Alimentos ou produtos alimentícios; } \\
\text { Seu beneficiamento, não } \\
\text { abrangido por outras classes }\end{array}$ & $\mathrm{L}$ & $\begin{array}{l}\text { Alimentos, produtos alimentícios ou } \\
\text { bebidas não alcoólicas, não abrangidos } \\
\text { pelas subclasses A21D ou A23B- } \\
\text { A23J; Seu preparo ou tratamento, } \\
\text { por exemplo, cozimento, modificação } \\
\text { das qualidades nutritivas, tratamento } \\
\text { físico; Conservação de alimentos ou } \\
\text { produtos alimentícios, em geral }\end{array}$ \\
\hline A61 & $\begin{array}{l}\text { Ciência médica ou } \\
\text { veterinária; Higiene }\end{array}$ & $\mathrm{P}$ & $\begin{array}{c}\text { Atividade terapêutica específica } \\
\text { de compostos químicos ou } \\
\text { preparações medicinais }\end{array}$ \\
\hline
\end{tabular}

Fonte: Elaborada pelos autores deste artigo a partir da tabela de classificação da WIPO

Com o auxílio desses dados, pode-se, mais uma vez, ver que a utilização medicinal do trigo sarraceno é muitas vezes introduzida pelo seu consumo direto, número muito superior 
ao uso de apenas um dos seus compostos, já que, como foi dito anteriormente, apenas 2,8 $\%$ das patentes faz referência a atividades terapêuticas específicas de compostos químicos ou suas preparações para uso humano e animal. Entretanto, sabe-se que a relação com os demais componentes pelo consumo pode ser muito favorável, por isso, as patentes das categorias A23 e A21 não excluem seu uso terapêutico, apenas apresentam um estado da arte que envolve a conservação ou beneficiamento de um produto para o mesmo fim.

Complementando os estudos anteriores, a Figura 8, chamada de "cluster", cujo nome está relacionado à abordagem gráfica, está dividida da seguinte forma: a divisão é feita por áreas que representam a similaridade semântica entre três temas abordados; o tamanho das áreas é coerente com a densidade de pontos, os quais expressam as patentes ou família de patentes estudadas. Vê-se que alguns pontos permeiam outras áreas, o que demonstra a proximidade e relação entre os temas das patentes. Essa abordagem gráfica torna visível a relação de todos os temas que já foram trabalhados com o material central da abordagem deste trabalho.

Figura 8 - Cluster das áreas de pesquisa de patentes depositadas

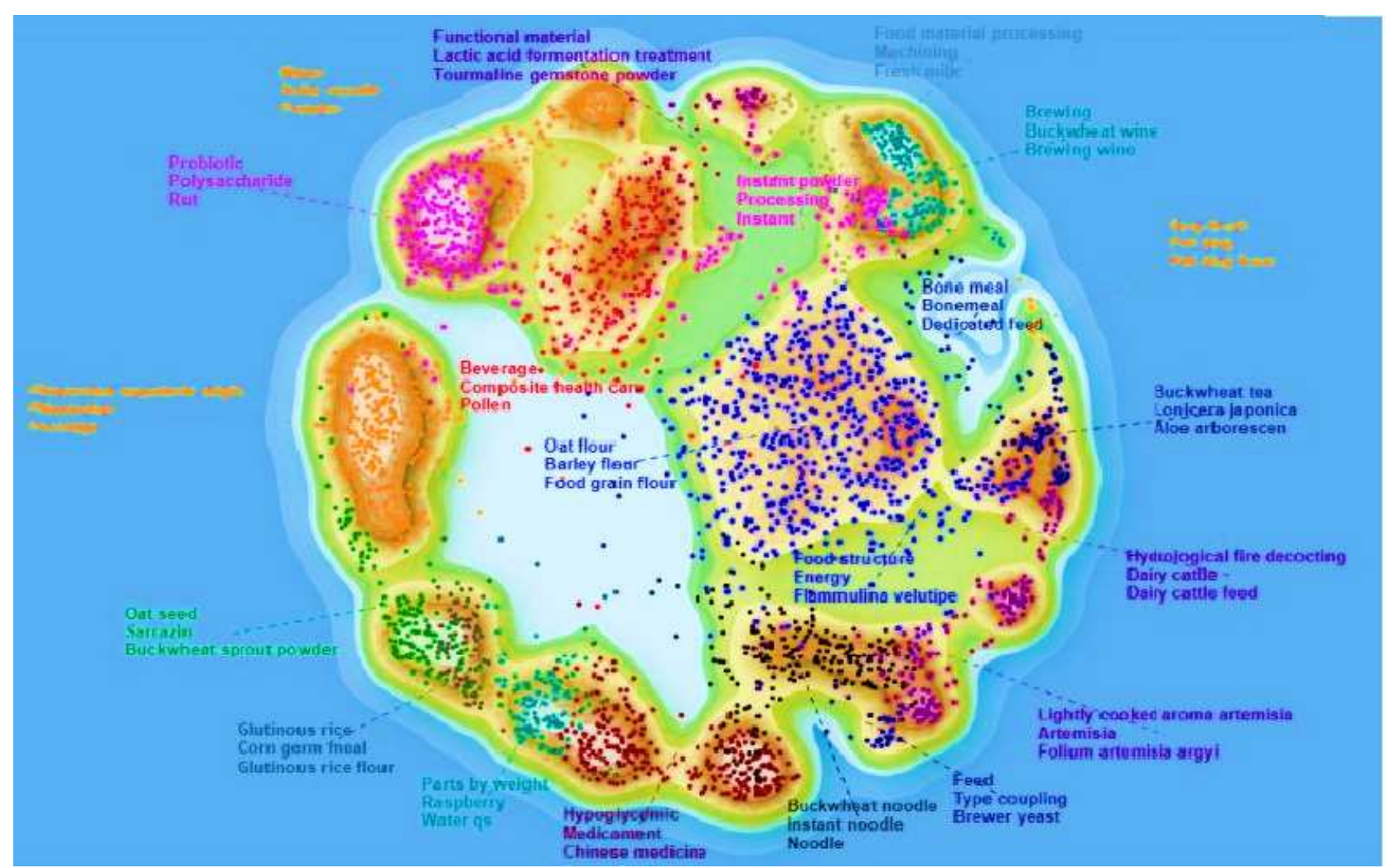

Fonte: Orbit (2019)

Como análise preliminar da Figura 8, vê-se uma grande área no centro da figura (pontilhado azul ), que relaciona os assuntos de farinha de aveia, cevada e grãos, como esperado de acordo com as discussões anteriores sobre a maneira como é empregado na forma de alimento. As pesquisas mais abordadas tratam da substituição de farinhas providas de trigo e cevada por farinha de trigo sarraceno e aveia, na tentativa de diminuir ou eximir a concentração de glúten nos alimentos preparados. É nessa área também que se pode relacionar as patentes das categorias A21D e A23L, que tratam da conservação, preparo e beneficiamento de alimentos por meio da criação de novos maquinários ou processos de preparo. 
Ainda na área relacionada a farinhas, percebe-se que os pontos são permeados a diversos outros temas relacionados à alimentação, a exemplo da área em preto que trata dos temas como preparo de macarrão e massas, assim como uma área em azul claro que trabalha o tema de preparo de chás e bebidas asiáticas. Finalmente, a área que vai de encontro a medicina chinesa, em vermelho no canto inferior central, também é permeada pelas patentes relacionadas à farinha. $\mathrm{O}$ interessante nessa análise é entender que existe um caminho científico favorável ao tratamento de insumo na medicina, além do apresentado pelo consumo do trigo sarraceno.

Analisando os pontos marginais do gráfico, tem-se a área que aborda os temas probióticos, polissacarídeos e rutina (em rosa no canto superior esquerdo), uma pequena área no canto superior central que trata da utilização do material do grão como material funcional de precursor para fermentação com ácido láctico e o seu uso com adição de pó de turmalina com sentido terapêutico em travesseiros, por exemplo. Fazendo um paralelo com a classificação CIP, essas patentes dizem respeito às categorias A23L e A61P.

Utilizando o direcionamento desse estudo, diversas áreas se relacionam à utilização do trigo sarraceno na cerveja e em outros meios de produção de bebidas, sendo elas a pesquisa que já avança nesse sentido. Pode ser verificado na área de produção de bebidas alcoólicas, como vinhos (em azul claro no canto superior direito), estando estreitamente relacionada com a área de processamento e pó instantâneo.

Evidenciando a prospecção tecnológica do trigo sarraceno, fez-se a prospecção científica na busca de artigos por meio do operador "OR" para as buscas 2, 3, 4, 6 e 9 apresentados na Tabela 1, correspondeu a 1.062 publicações nas áreas de tecnologia e ciência dos alimentos, química aplicada e nutrição, como visto em Figura 10. A combinação dos termos escolhidos dessa maneira engloba toda a produção que associa o trigo sarraceno a alimentos, fabricação de bebidas fermentadas, produtos sem glúten e bebidas (buckwheat + food; brew*; gluten free; beverages), assim como a pesquisa para cerveja sem glúten (beer + gluten free). Termos como "brew*" e "beverage" foram utilizados no contexto de indicar que existem bebidas fermentadas ou não que podem utilizar o trigo sarraceno, mas não necessariamente para o produto cerveja. Da mesma forma que a combinação entre "beer" e "gluten free" pode englobar cervejas sem glúten que não necessariamente utilizem o trigo sarraceno para conferir essa propriedade.

Assim, vale pontuar na Tabela 1 algumas dessas condições. A busca de número 6 da combinação dos termos "beer" e "gluten free" resultou em 92 artigos publicados no período analisado. Já para a busca de número 8 com os termos "buckwheat" e "beer", foram encontrados 32 artigos, adicionando o termo "gluten free" (busca número 10), essa quantidade ainda diminui mais, chegando a 20 artigos. Tal fato evidencia que nem todas as pesquisas relacionadas à cerveja sem glúten necessariamente se referem ao trigo sarraceno (apesar de que ele tem uma participação importante nesse segmento), estando, assim, relacionadas a cereais e peseudocereais, como arroz, milho, milheto, sorgo e quinoa, que também não apresentam glúten e podem ser integrados às cervejas desse tipo.

Pode-se observar que os setores da agricultura, biotecnologia e toxicologia são diversamente citados, o que foi atribuído a uma função recorrente da planta de trigo sarraceno quanto à fixação de fósforo no solo, ao aumento de nutrientes para as culturas posteriores e, finalmente, aos benefícios do uso da planta como palhagem. 
Figura 9 - Domínios relacionados a publicações
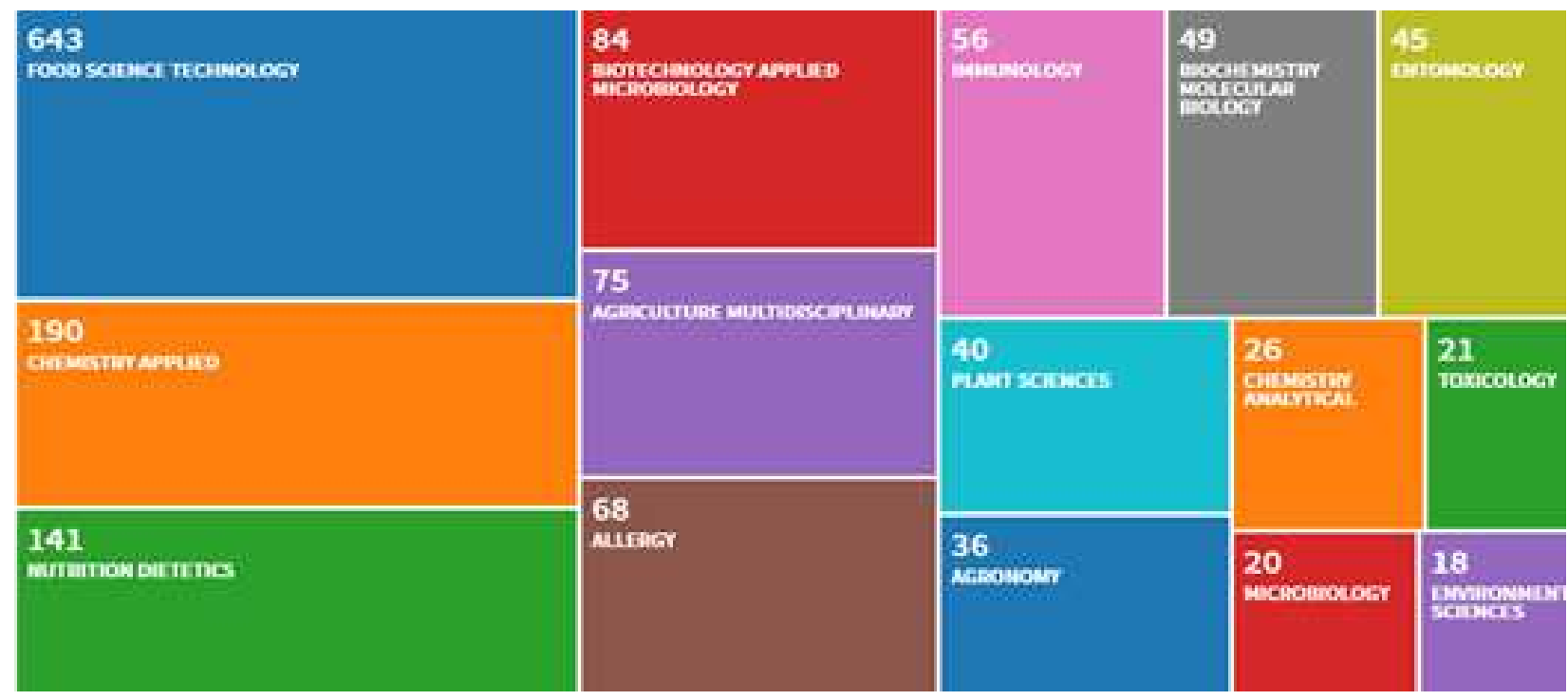

Fonte: Web of Science (2019)

Ainda sobre a Figura 9, vê-se que os artigos seguem uma tendência pela pesquisa discricional do grão ao que se refere a sua composição e utilização em alimentos, seguindo o nicho de revistas na área de nutrição, medicina e de tecnologia de alimentos. Entre os artigos, muitos estudos têm objetivos comparativos, estudando as composições de cereais e pseudocereais por diversas metodologias, que acabam por exaltar as propriedades benéficas do grão, principalmente no que diz respeito a sua carga proteica. Entretanto, é comum que qualquer alimento não apresente apenas benefícios, por isso artigos são produzidos no sentido de estudar e de revisar moléculas fitoquímicas que apresentem adversidades ao consumo humano. A exemplo tem-se o artigo de Mattila e Pihlanto (2018) a respeito de um estudo comparativo entre as sementes de linhaça (Linum usitatissimum), quinoa (Chenopodium quinoa), fava (Vicia faba), trigo sarraceno (Fagopyrum esculentum) e outros, analisando alguns compostos fitoquímicos que poderiam ser benéficos e aqueles chamados de "antinutricionais" ou não nutritivos.

No estudo, constatou-se que a farinha de trigo sarraceno tem alta carga fenólica, um composto com propriedades capazes de reduzir riscos de doenças cardiovasculares, diabetes e osteoporose, entretanto, os taninos condensados, também uma classe de polifenóis, considerado um composto antinutricional, pela sua capacidade de ligação com algumas proteínas e amido, impedindo o uso ou captação desses compostos pelo organismo humano e animal. Quando o estudo foi direcionado a esse tipo de polifenol, além da quantificação dos inibidores de proteases, o trigo sarraceno também apresentou altos níveis na comparação com os demais materiais (199 $\pm 4 \mathrm{mg} / 100 \mathrm{~g}$ de material seco), tendo ficado em segunda posição na correlação entre as quantidades de taninos e em primeiro lugar quando o potencial do inibidor de tripsina, inibidor de proteases, foi comprovado (MATTILA; PIHLANTO, 2018).

Com esse dado, a Figura 10 demonstra a tendência de crescimento das pesquisas durante os anos, com uma série de variações em seus números no decorrer dos anos avaliados, mas de forma geral apresentando uma curva crescente ao longo dos anos. 
Figura 10 - Artigos por ano de publicação

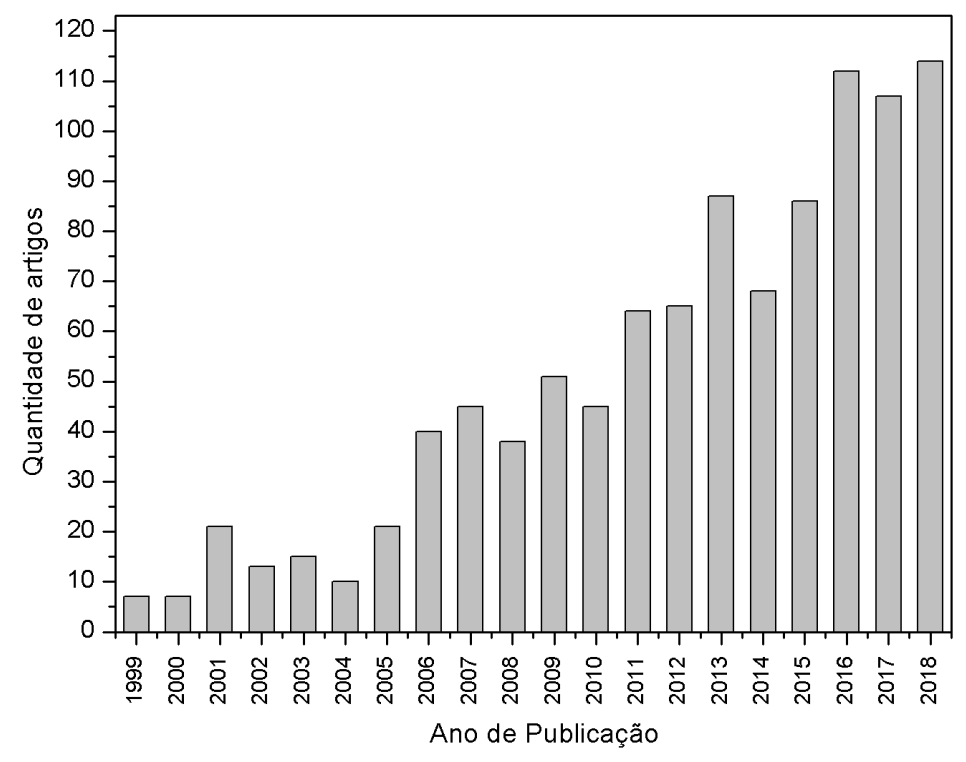

Fonte: Elaborada pelos autores deste artigo com dados do Web of Science (2019)

O crescimento no número de publicações, destacado na Figura 10, revela não só um interesse na utilização do trigo sarraceno em diversos setores, mas também acompanha fenômenos globais como o crescimento populacional e, consequentemente, o crescimento no consumo de alimentos, a diversificação do mercado, que, por sua vez, abre portas para especificidades relacionadas a esses produtos, como o segmento dos alimentos sem glúten e a possibilidade de incorporar novos itens alimentícios à dieta diária.

No caso do mercado cervejeiro, essa crescente também é evidenciada não só no que diz respeito a artigos e patentes. $\mathrm{O}$ consumo e a produção de cerveja no mundo aumentaram de forma exponencial nos últimos anos, especialmente no Brasil posicionando-se como o terceiro maior produtor de cerveja no mundo (140 milhões de hectolitros), ficando atrás apenas da China e dos Estados Unidos (dados de 2016) (LIMA et al., 2017). Com o aumento da produção de cerveja, aumenta-se a demanda por matérias-primas, nesse contexto, surge a necessidade de diversificar os elementos adicionados à cerveja, e outros cereais e matérias-primas passam a ser utilizados nas receitas.

Buiatti, Bertoli e Passaghe (2018) avaliaram o incremento de pseudocereais que não contêm glúten (milheto, amaranto, trigo sarraceno e quinoa) como adjuntos em cervejas e concluiu que a presença destes na bebida conferia não só a diminuição no teor de glúten como também o aumento da estabilidade coloidal. Destaca-se que o melhor pseudocereal foi o trigo sarraceno que, após processo de malteação, obteve os melhores resultados de rendimento somados à carga proteica e fenólica, capaz de agregar a estabilidade coloidal destacada.

Diferente do observado para patentes, o país que mais produz artigos é o Japão, como apresentado na Figura 11, seguido da China. Como os maiores depositantes de patentes são indústrias, o perfil de produção de artigos é diferente, uma vez que a cultura de divulgação de resultados não tem fins comerciais. 
Figura 11 - Países com maior número de publicações

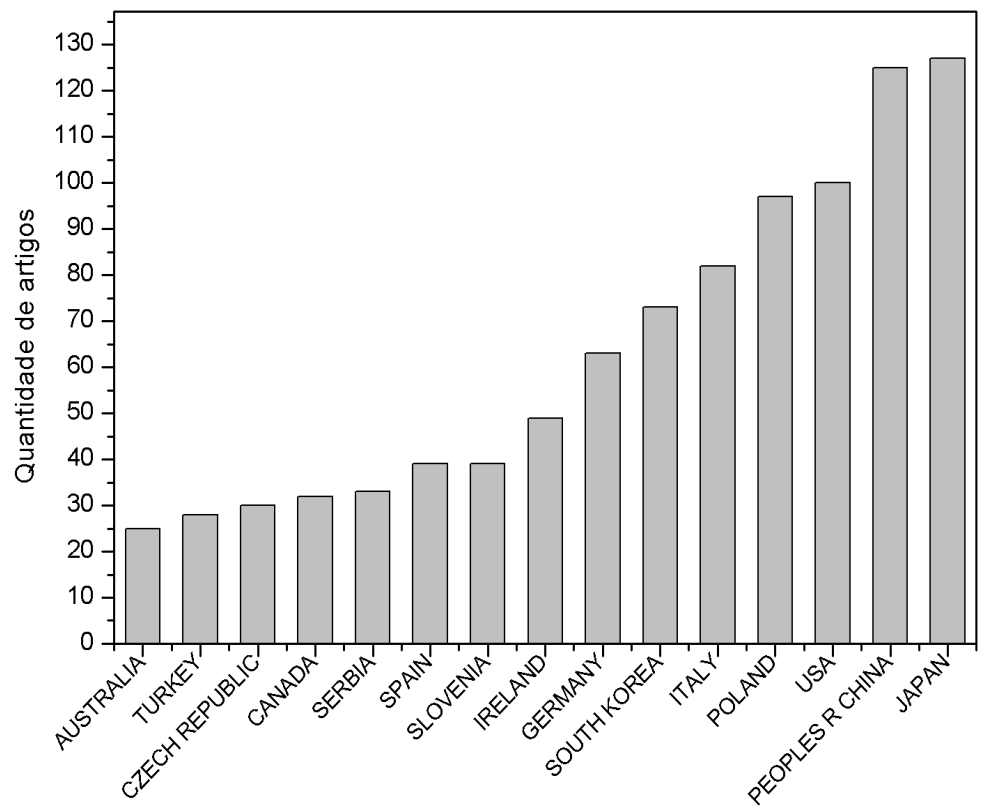

Fonte: Elaborada pelos autores deste artigo com dados do Web of Science (2019)

\section{Considerações Finais}

O trigo sarraceno é considerado um pseudocereal que se assemelha muito aos cereais comumente conhecidos e usados como o trigo comum, entretanto, várias propriedades, que vão desde seu cultivo até sua utilização, mostram sua versatilidade e peculiaridades inerentes ao grão. Por não conter glúten e ser rico em proteínas, esse grão tem sido utilizado em diversos alimentos, em especial, na cerveja, que é comumente produzida com malte de cevada, que impossibilita o consumo dessa bebida tão popular por pessoas alérgicas e/ou intolerantes. Além disso, mesmo que não muito conhecido, o grão tem uma produção nacional e mundial expressiva e já participa de forma considerável como commodity comercial.

Pela prospecção por patentes e artigos científicos, observou-se que o trigo sarraceno está inserido no mercado e na academia de forma diversa, seja na sua utilização na produção de alimentos e como insumo terapêutico em alguns casos, estando relacionado à ciência dos alimentos e à biotecnologia. Em especial para produção de cerveja, tanto as novas tecnologias estão sendo desenvolvidas como as pesquisas na área de alimentos sem glúten que incluem, dessa forma, a bebida destacada. Na comparação da produção de patentes e artigos, os documentos patentários estão em maior quantidade e demonstram um interesse comercial com o pseudocereal, ao mesmo tempo, os artigos, embora em menor quantidade, acompanham um ritmo crescente ao longo dos anos e destacam que a academia começa a trazer questões da investigação básica sobre a utilização do trigo sarraceno e outros grãos sem glúten na área de alimentos e farmacêutica. 


\section{Agradecimentos}

Os autores agradecem o suporte financeiro oferecido pela Coordenação de Aperfeiçoamento de Pessoal de Nível Superior (CAPES) e pelo Conselho Nacional de Desenvolvimento Científico e Tecnológico (CNPq).

\section{Referências}

APK-INFORM INFORMATION AGENCY. Ukraine: stocks of buckwheat totaled 36.4 thsd tonnes as of February 9. 2011. Disponível em: https://www.apk-inform.com/en/news/104744. Acesso em: 16 jun. 2019.

BOLAND, M. Buckwheat Profile: Agricultural Marketing Resource Center. [2016]. Disponível em: http://www.agmrc.org/commodities-products/specialty-crops/buckwheat-profile/. Acesso em: 20 nov. 2016.

BUIATTI, S.; BERTOLI, S.; PASSAGHE, P. Influence of gluten-free adjuncts on beer colloidal stability. European Food Research and Technology, [S.I.], v. 244, n. 5, p. 903-912, 2018.

CHRISTA, K.; SORAL-ŚMIETANA, M. Buckwheat grains and buckwheat products - Nutritional and prophylactic value of their components - A review. Czech Journal of Food Sciences, [S.l.], v. 26, n. 3, p. 153-162, 2008.

COMEX STAT. [Base de dados do Ministério da Economia - Internet]. Comex Stat. 2019.

Disponível em: http://comexstat.mdic.gov.br/pt/geral. Acesso em: 14 abr. 2019.

ELSAYED, M. et al. Energy potential from buckwheat husks through a thermochemical and biochemical approaches. In: EUROPEAN BIOMASS CONFERENCE AND EXHIBITION PROCEEDINGS. 2017.

KNOX, O. G. G. et al. Improved screening of biochar compounds for potential toxic activity with microbial biosensors. Environmental Technology and Innovation, [S.1.], v. 9, p. 254-264, 2018. Disponível em: https://doi.org/10.1016/j.eti.2017.12.007. Acesso em: 14 abr. 2019.

KREFT, I.; FABJAN, N.; YASUMOTO, K. Rutin content in buckwheat (Fagopyrum esculentum Moench) food materials and products. Food Chemistry, [S.l.], v. 98, n. 3, p. 508-512, 2006.

KUNZE, W. Technology Brewing and Malting. 3. ed. Berlim: VLB, 2004.

KUZMICHEV, V. Exportação de grãos é interrompida até 2011. Russia Beyond BR, 2010.

Disponível em: https://br.rbth.com/articles/2010/09/13/exportacao_de_graos_e_interrompida_ ate_2011_12003. Acesso em: 14 jun. 2019.

LAZDOVICA, K. et al. Comparative study on thermal pyrolysis of buckwheat and wheat straws by using TGA-FTIR and Py-GC/MS methods. Journal of Analytical and Applied Pyrolysis, [S.l.], v. 124, p. 1-15, 2017. Disponível em: http://dx.doi.org/10.1016/j.jaap.2017.03.010. Acesso em: 14 jun. 2019.

LIMA, L. A. et al. Sinopse do cenário cervejeiro: o advento da produção e o mercado na região centro oeste. Cadernos de Prospecção, Salvador, v. 10, n. 4, p. 650-664, 2017. 
MATTILA, P. H.; PIHLANTO. A. Contents of phytochemicals and antinutritional factors in commercial protein-rich plant products. Food Quality and Safety, [S.I.], v. 2, n. 4, p. 213-219, 2018.

MENAFN. Global Buckwheat Market 2018-2025. Research, Trends, Major Producers and Forecast. [2018]. Disponível em: https://menafn.com/1097547836/Global-Buckwheat-Market20182025Research-Trends-Major-Producers-and-Forecast. Acesso em: 27 jun. 2019.

OLIVEIRA, L. P. et al. Prospecção Tecnológica da Utilização de Catalisadores Carbonáceos Ácidos na Produção de Biocombustíveis, Caderno de Prospecção, Salvador, v. 11, n. 4, p. 1.136-1.149, dezembro, 2018.

ORBIT INTELLIGENCE. [plataforma de busca online - Internet]. Orbit Intelligence- Questel. 2019. Disponível em: https://www.orbit.com. Acesso em: 8 abr. 2019.

RIBEIRO, N. J. Desenvolvimento de Cerveja Funcional sem Glúten a partir de Mandioca e Trigo Sarraceno. Florianópolis: EdUFSC, 2016.

SIMOES, A. OEC. Buckwheat (HS92: 1008) Product Trade, Exporters and Importers. [2019]. Disponível em: https://atlas.media.mit.edu/en/profile/hs92/1008/. Acesso em: 27 jun. 2019.

TOMOTAKE, H. et al. Physicochemical and functional properties of buckwheat protein product. Journal of Agricultural and Food Chemistry, [S.l.], v. 50, n. 7, p. 2.125-2.129, 2002.

WEB OF SCIENCE. [Base de dados - Internet]. Web of Science. 2018. Disponível em: http://appswebofknowledge.ez54.periodicos.capes.gov.br/ Acesso em: 17 abr. 2019.

VEIT, P. Processo de Fabricação de Cerveja sem Glúten. 2014.

\section{Sobre os Autores}

\section{Viviane Cristina Buge Brasil}

E-mail: vivianebuge@gmail.com

Mestra em Química.

Endereço profissional: Laboratório de Bioprocessos Cervejeiros e Catálise Aplicada a Energias Renováveis, Instituto de Química, Universidade de Brasília, caixa postal 4478, Brasília, DF. CEP: 70904-970.

\section{Rafael Benjamin Werneburg Evaristo}

E-mail: rafael.werneburg@gmail.com

Mestre em Química.

Endereço profissional: Laboratório de Bioprocessos Cervejeiros e Catálise Aplicada a Energias Renováveis, Instituto de Química, Universidade de Brasília, caixa postal 4478, Brasília, DF. CEP: 70904-970.

\section{Bernardo Pontes Guimarães}

E-mail: bepontesgui@gmail.com

Bacharel em Química Tecnológica.

Endereço profissional: Laboratório de Bioprocessos Cervejeiros e Catálise Aplicada a Energias Renováveis, Instituto de Química, Universidade de Brasília, caixa postal 4478, Brasília, DF. CEP: 70904-970. 


\section{Grace Ferreira Ghesti}

E-mail: ghesti.grace@gmail.com

Doutora em Química.

Endereço profissional: Laboratório de Bioprocessos Cervejeiros e Catálise Aplicada a Energias Renováveis, Instituto de Química, Universidade de Brasília, caixa postal 4478, Brasília,DF. CEP: 70904-970. 